\title{
Psicanálise, Universidade e Capital Intelectual
}

Psychoanalysis, University and Intellectual Capital

Sérgio Scotti

Universidade Federal de

Santa Catarina

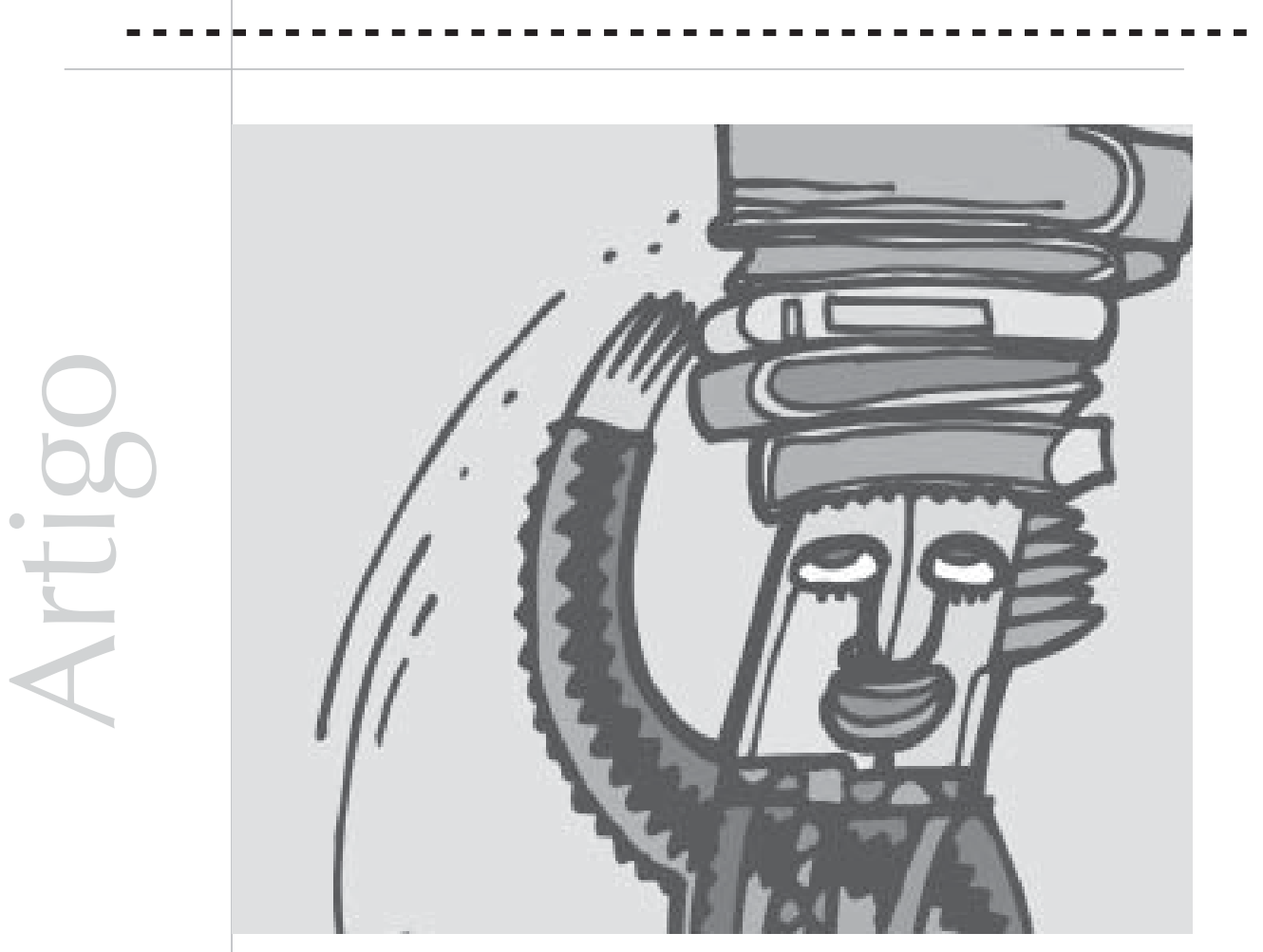




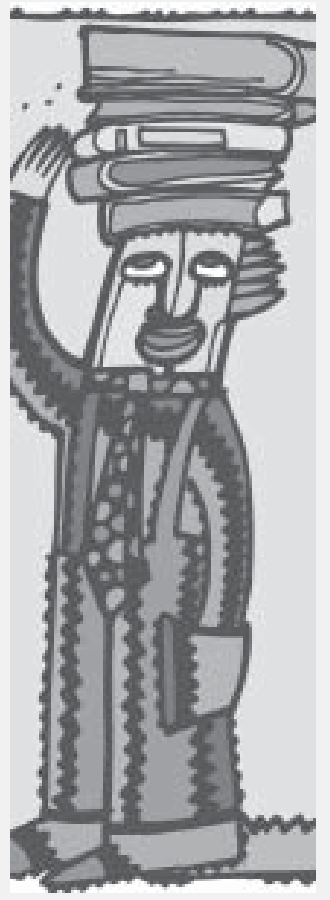

Resumo: este artigo trata da relação problemática entre a psicanálise e a universidade, tendo como ponto de partida o questionamento de uma prática produtivista na academia que aparece de forma sintomática na desvalorização do livro em relação aos artigos. Tal sintoma revela, em sua análise, o retorno do discurso capitalista no âmbito do discurso universitário, a partir do que se faz uma crítica à ciência em geral e à Psicologia em particular, tendo como referência a distinção entre saber e verdade na psicanálise e o conceito de Real de Lacan.

Palavras-chave: psicanálise, universidade, livro, artigo.

Abstract: this article deals with the difficult relationship between psychoanalysis and the university, having as its starting point the questioning of a productive practice in the academy that appears in symptomatic form in the depreciation of books in relation to articles. Such symptom reveals, in its analysis, the return of the capitalist discourse in the scope of the university discourse; departing from that, science in general and Psychology in particular are reviewed, having as reference Lacan's concept of Real.

Key words: psychoanalysis, university, book, article.

Hoje em dia, o intelectual brasileiro, especialmente aquele que atua nas universidades, vive uma situação sui generis, para não dizer esdrúxula. Para desenvolver suas pesquisas, atuar na pós-graduação e conseguir verbas para seus projetos, ele precisa produzir, pois há um sistema de avaliação que pontua a produção acadêmica conforme trabalhos apresentados em congressos, resenhas publicadas, artigos ou livros. Aqui começa a complicação.

Imagine-se a seguinte situação, verídica, por sinal: alguém defende sua tese de doutoramento e publica, na forma de artigo, um dos capítulos da mesma numa revista bem conceituada nacionalmente e avaliada como de nível A. Posteriormente, a mesma tese, agora na forma de livro, é publicada através de editora com conselho editorial, também favoravelmente conceituada.

Contudo, pelos critérios atuais de avaliação da produção acadêmica, o livro é pontuado abaixo do valor que recebe o artigo. Estranha lógica, que é justificada com o argumento de que "qualquer um pode publicar seu livro desde que tenha como pagar", além do que justificativa dada por um importante membro de comissão avaliadora da produção acadêmica nacional - "não há como se avaliar um livro".

Ora, existem, é claro, muitas formas de se avaliar a qualidade de um livro, da mesma forma que se avalia um artigo, a começar por se considerar a existência ou não de conselho editorial. Por outro lado, poder-se-ia estabelecer os critérios que as próprias editoras deveriam alcançar, tal como os periódicos, para que seus livros fossem avaliados. No entanto, atualmente, os livros, sejam quais forem, sem critério algum, caem na vala comum ou no limbo que se formou entre os artigos e as resenhas.

O livro, a despeito do enorme desenvolvimento das mídias eletrônicas e da 
Um livro tem seu valor por si próprio, como vimos, pelo que ele exige enquanto projeto intelectual e também enquanto objeto da cultura. Seuvalor é relativizado por sua relação com outros livros e seus leitores. inegável importância dos periódicos especializados, continua a ser ainda, ao nosso ver, a melhor forma de expressão e divulgação das idéias e conceitos que se desenvolvem na pesquisa. Que outro meio permitiria melhor o desdobramento e a elaboração de raciocínios ou argumentações a favor ou contra uma determinada tese, concepção ou teoria? Um livro que não seja somente a coleção de alguns textos escolhidos - o que não tira seu valor como tal - tem o peso de, para além de seu volume, representar um conjunto, um sistema, um corpo que deve ser tomado na sua totalidade. Só por isso, o projeto e a execução da escrita de um livro exige o desenvolvimento de um pensamento que não é o mesmo de um artigo. Num livro, encontramos, num mesmo corpo textual, as diferentes idéias do (s) autor (es) que, por semelhança ou divergência entre elas mesmas ou com as de outrem, permitem a reflexão do leitor dentro de um campo conceitual que é delimitado pelas páginas que o compõem. Isso não impede, obviamente, que outros textos, de livros ou não, do mesmo autor ou de outros, sejam cotejados entre si. No entanto, o livro, diferentemente de uma obra como um todo, permanece como referência pontual das idéias do autor, não da mesma forma que um artigo, pois a referência é sempre ao conjunto que o próprio livro forma.

É claro que não estamos defendendo a idéia de que um livro, pelo simples fato de ser um livro, seja melhor que um artigo, o qual pode conter idéias ou descobertas mais significativas que dezenas ou centenas de livros. Apenas queremos dar visibilidade ao fato de que, para além dos aspectos práticos implicados na construção e publicação de um livro, diferentemente do artigo, o livro propõe ao autor e ao leitor uma tarefa que exige fôlego e dedicação intelectual sempre maiores, embora se possa considerar todas as diferenças de qualidade entre os livros e/ou artigos escritos por um mesmo ou diferentes autores.
Então por que se avalia o livro abaixo do artigo? Já se vê que não é pelas qualidades intrínsecas de um e de outro nem pelas razões práticas que supostamente dificultam sua avaliação. Mais ainda: por que, ao menos, não se coloca os livros no mesmo nível que os artigos? Por alguma razão que, a princípio, nos escapa à compreensão, aquele que seria a expressão por excelência do empreendimento intelectual - o livro - tornouse, ao menos para as comissões avaliadoras, um produto de segunda categoria. Que lógica estaria pervertendo uma ordem de valores em que a parte (artigo) vale mais que o todo (livro), ainda mais quando os dois têm a mesma fonte? Talvez possamos começar a depreender tal lógica a partir da constatação inevitável de que o livro se tornou um produto desvalorizado.

Um livro tem seu valor por si próprio, como vimos, pelo que ele exige enquanto projeto intelectual e também enquanto objeto da cultura. Seu valor é relativizado por sua relação com outros livros e seus leitores. Além do mais, ele também é um produto de mercado.Sabemos que nem sempre um best-seller, um campeão de vendas, contém grande interesse intelectual. Será esse um dos motivos para a atitude desdenhosa em relação ao livro nas comissões avaliadoras?

Pelo contrário, parece que, de uma forma deveras enviesada, a lógica de mercado imiscuiuse no ambiente intelectual das universidades e agências de avaliação e fomento, pois o livro não é um bom produto para esse sistema, isso porque o sistema de produção intelectual universitário imita o sistema de produção capitalista e a lógica de mercado no que eles têm de pior, ou seja, a famigerada sociedade de consumo que se baseia na produção em massa e gerou a cultura do descartável, a qual se infiltra em todas as áreas da vida humana, inclusive das relações pessoais. Por que não se manifestaria naquela que deveria reger-se por padrões acadêmico/intelectuais, onde supostamente se busca o produto do conhecimento, o saber? 
O sintoma de tal contaminação sofrida pelo ambiente acadêmico dessa lógica produtivista que imita o sistema capitalista é a desvalorização do livro. Ele é um produto que não se encaixa muito bem no sistema. O livro, diferentemente do artigo, exige muito mais tempo de elaboração, não pode ser produzido em série. Exige, freqüentemente, anos de preparação e elaboração até estar pronto, exige também tempo e esforço de quem se debruça sobre ele. O artigo, por sua vez, permite a formação do que, em certa ocasião, uma colega de departamento chamou de "capital de giro". Enviam-se, em série, vários artigos para diferentes periódicos para que a "produção" não caia, isso sem falar nos casos em que critérios estranhos para uma publicação, mesmo de artigos, são exigidos, como, por exemplo, número mínimo de páginas. Mais que isso, comenta-se que algumas revistas começam a exigir pagamento dos autores cujos artigos publicam para sua manutenção ${ }^{1}$.

Uma das conseqüências dessa lógica produtivista é que a queda acaba sendo a da qualidade. A quantidade torna-se o principal, o que se reflete, por exemplo, na superior avaliação concedida a cursos de pós-graduação de caráter tecnicista que, por sua natureza, através de seus professores e alunos, produzem, rapidamente e em grande quantidade, artigos para consumo também rápido e descartável, tudo isso atrelado a um mercado de trabalho que exige profissionais cada vez mais rápida e agilmente preparados para a competição pelas parcas vagas disponíveis.

A assimilação da lógica capitalista se completa com um elemento indispensável, a exploração da força de trabalho. Os professores, envolvidos em suas diversas atividades, não poderiam manter-se "produtivos" se seus alunos não se dispusessem "alegremente" a produzir textos que serão assinados por seus orientadores. Finalmente, toda essa engrenagem, para funcionar a contento, deve ser azeitada com aquilo que move o mundo sempre, o dinheiro das verbas e bolsas acirradamente disputadas.

A reprodução do modelo capitalista dentro de instituições de ensino e pesquisa - que, supostamente, estariam à parte e até mesmo posicionadas contrariamente à lógica de mercado - manifesta-se também, inevitavelmente, naquilo que é um outro produto ou subproduto do sistema, ou seja, a segregação, a marginalidade daqueles que, por um motivo ou outro, não se inserem no modelo.

Além do caso livro/sintoma que acabamos de apontar, há um campo do saber que, em especial nas universidades, experimenta e ilustra exemplarmente tal marginalidade: a psicanálise.

Talvez a marginalidade seja a própria condição de existência da psicanálise, na universidade e na cultura em geral, como sugere Laplanche (1980), citado por Aguiar (2002) em Comentários sobre a Prática Universitária da Psicanálise. O psicanalista - que não participa, enquanto tal, nem do discurso capitalista nem do discurso universitário - talvez não tenha outra opção, para manter a especificidade de seu discurso, a não ser permanecer na marginalidade, posição difícil quando se trata de um professor universitário de quem é exigido manter-se "produtivo" dentro de um sistema do qual participa, mas do qual, ao mesmo tempo, percebe-se separado, mais não fosse pela posição crítica que se vê obrigado a assumir, pois como não perceber e apontar o retorno do recalcado no discurso universitário, o discurso capitalista?

Apesar de todas as aproximações possíveis entre o analista e o pesquisador universitário, através de termos tais como uma "leitura eqüiflutuante" de textos, sugerida também por Laplanche (1998), permanece o fato de que
1 Conforme informação em parecer de consultor ad hoc deste artigo. 
analista e pesquisador, embora possam os dois referir-se à mesma pessoa e a uma escuta analítica semelhante, estão em lugares diferentes. Ao analista, cabe analisar o inconsciente, e isso se dá numa relação transferencial específica. Isso é o que se espera dele, segundo Lacan (1992). Por outro lado, como pesquisador, ele não pode deixar de "escutar" e analisar um discurso que diz mais do que pretende. Noutras palavras, que é sintomático.

Esse é o caso do livro, acima referido, e também é o caso da resistência à psicanálise na universidade, de modo geral, e, de modo específico, dentro da própria Psicologia. Além do questionamento da "cientificidade" da psicanálise como método - que já provocou também outras aproximações, como à do método "qualitativo" - a psicanálise encontra resistências bastante concretas, até mesmo na composição dos currículos de Psicologia. É pertinente, portanto, questão de se propor disciplinas, cursos e até mesmo departamentos universitários com a denominação expressa de psicanalíticos - o que nos levaria à possibilidade da perturbadora idéia de uma universidade de psicanálise - o lugar do analista, seja lá onde for, é o daquele que, como lembra Lacan, se espera que analise.

E já que estamos falando em análise e em resistências, o que é que resiste? O que é que faz sintoma, que recalcado, retorna? O frescor da novidade, da descoberta de Freud, é o desejo, o sujeito do desejo de Lacan (1985). É sempre bom lembrar do que se está falando, e sempre estamos falando dele, do desejo, mesmo que esteja mascarado por fórmulas matemáticas, por planos metodológicos ou cálculos financeiros. A psicanálise não fala de outra coisa, o desejo inconsciente é sua matéria. Em última instância, é porque toca no desejo que a psicanálise cria resistência, seja onde for. $\mathrm{Na}$ universidade, como na cultura em geral, a psicanálise descobre o desejo lá mesmo onde se procura ocultá-lo. Não por um furor interpretativo, mas por um compromisso ético, o analista não recua, antes de tudo, diante de seu próprio desejo de analista. Como não reconhecê-lo, diante de si mesmo, como pesquisador? E o compromisso ético do analista não se prende unicamente ao desejo, mas, por conseqüência, ao que lhe faz barreira.

O discurso universitário, como qualquer outro discurso, desenvolve-se segundo as transformações metafórico/metonímicas que o recalcamento do desejo impõe. E o desejo, como lembrava Freud (1923/1973), é sempre o desejo sexual. Sexual no sentido freudiano de que a sexualidade inconsciente é sempre infantil, o que significa dizer que se trata de uma sexualidade fálica, regulada pela lógica fálica, na qual o que está em jogo é a posse do falo. Sabemos, portanto, que, em todos os discursos em torno dos quais gira a questão da sexualidade, do masculino ou feminino, ou de todas as questões de gênero, a questão subjacente é a do falo e de que lado ele está, o que significa dizer também de que lado está o poder. A política, enquanto formas possíveis de distribuição do poder, também está eivada de sexualidade.

No discurso universitário, o lugar do falo e, portanto, do poder, é ocupado pelo saber. Já houve tempo em que o saber era medido pela capacidade de se expressar na forma de um livro; hoje, são os artigos, quanto mais melhor. Em termos de avaliação acadêmica, por efeito do atual sistema, o saber pulverizou-se, fragmentou-se numa multidão de artigos. Diante dessa realidade, o projeto de um livro torna-se, de saída, algo desmotivador. O tempo e esforço exigidos não compensam o valor que lhe é atribuído.

O saber, como distingue Lacan (1985), não é coalescente à verdade. A psicanálise, através de Freud, criou um campo de saber que diz respeito ao inconsciente. No entanto, a 
verdade diz respeito ao desejo. A produção do saber nem sempre vai na direção da verdade. Até pelo contrário, há saberes que ocultam a verdade. No seio da própria psicanálise, Lacan (1985) identificou discursos e práticas supostamente sustentados por um saber que se afastava da verdade do desejo sexual. Não é à toa que, por essa via, tentou-se dessexualizar o desejo, torná-lo conforme ao ego. Toda essa lógica estava implicada numa política de formação do analista que o colocava sob o poder do "analista didata", suposto detentor do saber sobre o processo analítico.

A atual política de avaliação acadêmica reflete toda uma lógica que privilegia o saber em detrimento da verdade. A quantidade de artigos publicados, enquanto um produto que se tornou atrativo mais pelo seu valor de troca do que pelo seu valor de uso, pois é ele que garante o aporte de financiamentos, transformou-se no objeto fálico que cativa não tanto pela verdade que veicula, mas pelo saber que ostenta.

A verdade do desejo, que é o compromisso da psicanálise, é ocultada pelo compromisso da ciência que busca um saber totalizante. O saber psicanalítico sobre o desejo é um saber sobre a falta. Freud e Lacan (1991) demonstram que o desejo se estrutura a partir da impossibilidade de uma completude que o sujeito buscaria encontrar no Outro. A incompletude do outro materno leva a formas diversas de se buscar completá-lo, essa seria a função do falo de que o sujeito se faz cargo. O Real, o Outro ao qual a ciência se dedica a completar, como diz Lacan (1975-1976), é o impossível, e todo saber que se possa construir sobre ele será parcial. Todo desejo, então, nasce dessa falta, inclusive o desejo de saber; o próprio saber estará marcado por essa falta. É por isso que qualquer forma de saber, como o saber psicológico, por exemplo, nunca estará à altura da experiência humana. Não há como a ciência dar resposta àquilo que, por estrutura, será sempre falho, faltoso.
A busca de cientificidade dentro da Psicologia ressente-se de seus limites quando esta se depara com a psicanálise. Ela criou um campo de saber nos limites da própria Psicologia, que a questiona a partir de dentro, ou seja, quando se fala, por exemplo, em padrões de aprendizagem, fases de desenvolvimento, normas de comportamento, dinâmicas de interação grupais ou sociais, há sempre uma variável que subverte eventualmente as possíveis predições, ou racionalidades inerentes ao processo que se busca compreender: o sujeito do inconsciente, aquilo que aponta justamente a falta, o furo.

Em todo sistema totalizante, que, como a ciência, busca cercar o fenômeno - ou o Real, como diria Lacan - através de um discurso (teorias, fórmulas, leis...), aparece sempre o furo, a falta, isso porque é próprio de todo discurso, do simbólico, que ele não dê conta do Real. O sujeito do desejo é justamente esse sujeito da falta que aparece nos sintomas, nas formações do inconsciente, naquilo que não se encaixa nas estruturações do simbólico que, se surgiu de uma falta, produz ele próprio essa falta no mesmo ato em que se tenta tamponá-la. Essas pontas do Real, como diria Lacan (1975-1976), que aparecem nos sintomas, são a matéria do psicanalista, que deve preservar o lugar da falta - com seu silêncio ou interpretações - para que o desejo, a singularidade do sujeito, surja. Tanto na clínica quanto na academia o lugar do analista é o de preservar essa singularidade que, muitas vezes, se choca com o ideal cientificista de um saber totalizador.

A ciência - e, mais propriamente, a Psicologia, que perdeu toda a visão de conjunto do humano, parcializando-o, fragmentando-o numa série de especialidades sociais, organizacionais, educacionais ou clínicas busca amparar-se no mito de uma cientificidade que poderia dar-lhe a ilusão de um todo, sempre em vias de esfacelar-se. E a cientificidade se mede hoje em artigos. 
O artigo que seria a expressão parcial de um saber em vias de estruturar-se numa visão de conjunto, na forma de um livro, por exemplo, tornou-se objeto fálico, objeto de desejo, valorizado não pelo seu valor intrínseco e nem pelo seu valor acadêmico próprio, mas por uma lógica extremes à academia, uma lógica de mercado que não visa nem ao saber e ainda menos à verdade, pois tem seu valor sobredeterminado por aquilo que pode gerar de capital ${ }^{2}$. Em contraposição, o livro, que ainda se mantém, principalmente pelo valor de uso, perdeu seu valor no sistema de trocas no qual o artigo se transformou, na verdade, em moeda. Daí pensar-se no artigo como capital a ser acumulado. A verdade não se acumula, ela se desprende da pesquisa como resultado de um esforço investigativo que deveria encontrar no livro e/ou no artigo formas de expressão e elaboração. No entanto, em função da lógica produtivista, o artigo tem o seu valor pervertido, pois não se referencia naquilo que veicula de saber ou verdade intrínseca, mas encontra seu valor referenciado num sistema que não tem nada a ver com o conhecimento em si, e sim, na etiqueta (grife) que recebe quando é chancelado pelas revistas mais valorizadas no mercado.

Poderia dizer-se que tal crítica não leva em conta o valor científico real dos artigos nem a idoneidade dos pareceristas ad hoc. $\mathrm{Na}$ verdade, apesar de tudo, as pesquisas, na sua maioria, são sérias e os pareceres também. Eles buscam a qualidade e a consistência teórico-científica das pesquisas e estudos que fundamentam os artigos. Contudo, o valor de tudo isso fica subsumido pelo fator quantitativo que é aquele que, em última instância, regula o valor dos artigos. Não adianta se saber, para as comissões de avaliação, o valor intrínseco de um artigo ou livro per si, naquilo que ele(s) $\operatorname{traga}(m)$ de revelação ou novidade para o conhecimento, mas sim, quantos foram publicados nas revistas A, B ou C.
Mas essa questão do livro é somente uma ponta do iceberg. Por baixo dela, há toda uma massa de problemas que permanece submersa, mas que nem por isso deixa de produzir seus efeitos. Nos departamentos e institutos universitários, tem-se o clima próprio das sociedades segregacionistas. Aqueles que se engalfinham pelas verbas e bolsas de pesquisa através de sua "produtividade" mantêm-se à parte do "submundo" do ensino de graduação, relegado àqueles que, na tarefa de ensinar simplesmente, são desvalorizados e assoberbados pela grande quantidade de horas de ensino a que têm de se dedicar.

Essa "casta superior" que se encontra nos programas de pós-graduação fecha-se cada vez mais à entrada de novos elementos, através de critérios mais e mais restritivos, em função de seus próprios interesses. Esses critérios são defendidos com argumentos pseudocientíficos, como o da "produtividade". No entanto, nada mais são do que critérios de auto-referência, sem preocupação com a inclusão do diferente e, muito menos, do divergente, ou seja, de tudo aquilo que se afasta do critério cientificista e totalizante que impregna o discurso universitário, através de uma suposta mestria do saber medida em títulos e publicações. Por outro lado, o único acesso a esse Olimpo é o sujeito submeterse às "orientações" dos que já estão lá, onde não faltam as adulações, rivalidades, disputas por prestígio e poder.

O que não se sabe é até que ponto isso se reflete no ensino de graduação enquanto ganhos para o estudante iniciante, que se beneficiaria de um maior conhecimento adquirido pelos seus mestres, doutores ou pós-doutores que estão, por sua vez, cada vez menos dispostos a descerem do Olimpo. E então o ciclo se fecha, alimentando, assim, o ideal da pós-graduação, que é o de manterse o mais longe possível da desvalorizada graduação. 
Aos que não se encaixam no sistema, resta continuarem suas aulas e pesquisas sem as benesses das agências de fomento na labuta da graduação. A psicanálise, enquanto uma "douta ignorância", praticada nos consultórios das clínicas-escola e/ou nas salas dos supervisores de estágio, sobrevive academicamente em função dos trabalhos de pesquisa que procuram adaptar-se, a todo custo, aos critérios científico/acadêmicos mais relaxados do "qualitativo". Há que se lembrar que há exceções, os poucos cursos de pósgraduação em psicanálise que são como oásis para psicanalistas pesquisadores. Eles surgiram nos grandes centros urbanos, onde a psicanálise se impôs a partir de uma atuação clínica reconhecida, que rendeu frutos no interior de centros acadêmicos mais permeáveis ${ }^{3}$.

Contudo, a regra geral da "produtividade" promove, paradoxalmente, as condições para aquilo mesmo que se criticou na chamada proposta de "reforma universitária", ou seja, a criação de centros de excelência onde se desenvolveriam as pesquisas "avançadas", enquanto o ensino de graduação seria absorvido cada vez mais pelas instituições particulares, as quais, contraditoriamente, recebem os maiores incentivos do Estado, ao passo que o ensino público morre à míngua.

Dessa forma, concretizar-se-ia plenamente o projeto capitalista embutido na ideologia do produtivismo, enquanto os "excelentes" poderiam, do alto de seu Olimpo, lamentarse da péssima qualidade do ensino de graduação, como hoje em dia já se lamentam os professores universitários do péssimo ensino que se desenvolve no nível médio. O curioso de tudo isso é que se pensa que, através da excelência da pesquisa, poder-seia elevar o nível do ensino de graduação. $\mathrm{O}$ que acontece, na realidade, é que eles se afastam cada vez mais, perdendo-se de vista o principal produto, que deveria ser o próprio aluno e o futuro profissional que se forma na universidade, o qual só terá condições de competir no mercado de trabalho com o título de Mestre ou Doutor, fechando-se assim, novamente, o círculo.

E, por falar em fechar o círculo, voltamos à questão do livro. Só se poderia pensar nele como algo acessível ao estudante caso ele não fosse também um produto de mercado que, cada vez mais, se torna inacessível, não só pelo preço - abusivo até mesmo para o salário de um professor - como também pelo fato de que se torna cada vez mais raro, tanto devido às dificuldades de publicação quanto pelo desinteresse que o atual sistema de avaliação acadêmica produz quando classifica o livro abaixo do artigo. Normalmente o artigo tem vida mais curta que o livro. Enquanto produto descartável, deve ser substituído permanentemente pela produção mais recente, mais atual, como se a data de validade estivesse sempre para ser vencida, como se a qualidade de um escrito estivesse na dependência direta de ser recente.

Nós, da psicanálise, sabemos do permanente frescor que a releitura de um Freud dá às questões mais atuais da clínica contemporânea, por exemplo. A obra de Freud sempre estará lá nos seus escritos, nos seus livros, que são uma referência permanente. Claro que a perenidade de um saber não está garantida pelo fato de estar num livro, mas pela sua aplicabilidade, pelo seu poder heurístico, o que deveria nortear a avaliação de qualquer produção, inclusive a dos artigos, que, no entanto, têm sido avaliados pelas comissões de avaliação de pós-graduação mais pelo seu número e prazo de validade do que pelo seu valor intrínseco.

A que nos leva essa situação? A um permanente e crônico distanciamento da academia em relação à sociedade, pois se, por um lado, há todo um discurso de inclusão e de aproximação do saber acadêmico em relação ao social, por outro, há toda uma prática que tem como objetivo maior a
3 Como nas Universidades Federal e Estadual do Rio de Janeiro 
manutenção do próprio sistema acadêmico com todos os seus mecanismos restritivos de acesso ao saber e ao conhecimento, através dos filtros que se corporificam nos meandros da pós-graduação e das políticas de fomento à pesquisa.

Apesar de tudo, a melhor e mais importante pesquisa que se desenvolve em nosso país é a das universidades públicas, além das intervenções e participações das mesmas em projetos sociais que trazem evidentes benefícios para a população, como, por exemplo, as pesquisas com células-tronco ou a participação de psicólogos em trabalhos hospitalares que promovem a humanização necessária aos mesmos.

No entanto, permanece um fato incontestável: a universidade pública é para poucos e continuará para poucos enquanto reproduzir em seu próprio seio a lógica das relações capitalistas, lá mesmo onde se supõe que ela estaria à parte das determinações que engendram o capital, a saber, no plano intelectual. A "produção" em massa e em série de artigos, papers, garante a uns poucos a concentração de riqueza/recursos/fomento às custas da exploração do trabalho de alunos/ orientandos/bolsistas, os quais irão, no futuro, garantir seu lugar na classe privilegiada que detém o poder acadêmico do mestre sobre o aluno, o que mantém, de qualquer forma, seu parentesco com o escravo que, por sua vez, só conseguirá sua liberdade/diploma após um longo período de duras provas, nas quais terá que dar testemunho do adestramento a que é conduzido para tornar-se, ele mesmo, um representante do sistema que se auto-alimenta permanentemente.

Uma universidade realmente "aberta" - como já se tentou há tempos em nosso país ${ }^{5}$ - e democrática, não poderia ser concretizada apenas com a construção de novos campus, contratação de professores e abertura de vagas para mais alunos se a própria concepção do saber e do conhecimento não for democratizada, erradicando-se a concepção de mestria que se aproxima da do senhor - uma posição diferente da histérica, sempre à procura de um mestre ou do obsessivo, tentando a todo custo tampar a falta com o significante-buscando-se o compartilhamento de experiências e saberes a partir da questão que nos é comum a todos: o que fazer com esse Real que é impossível de se dizer todo e de nossa castração diante dele? A resposta em que a psicanálise aposta é de que não devemos abrir mão de nosso desejo.
4 Lacan, em seu Seminário 17, O Avesso da Psicanálise, mostra a proximidade entre 0 discurso do senhor e do escravo e o discurso universitário.

5 Referimo-nos à universidade idealizada por Darcy Ribeiro durante o governo de João Goulart. 
Sérgio Scotti Psicanalista, professor-adjunto do Departamento de Psicologia da Universidade Federal de Santa Catarina, doutorado em Psicologia clínica pela USP com a tese "A Estrutura da Histeria em Madame Bovary".

R. Jornalista Alírio Bossle, 421, João Paulo, Florianópolis, S.C., cep 88030-510. Tel. (48) 3238-3380 res., (48) 3331-9283 com., (48) 9961-1011 cel. E-mail:sscotti@mbox1.ufsc.br

Recebido 06/10/05 Reformulado 26/01/06 Aprovado 29/05/06

AGUIAR, F. Comentários Avulsos sobre a Prática Universitária da Psicanálise. São Paulo:Psicanálise e Universidade, no. 16, 2002, pp. 93-116.

FREUD, S. La Organización Genital Infantil (Adición a la Teoria Sexual), vol. 3. In Obras Completas. Madrid: Biblioteca Nueva, (1923)1973.

LACAN, J. O Seminário, Livro 2. O Eu na Teoria de Freud e na Técnica da Psicanálise. Rio de Janeiro: Jorge Zahar Ed., 1985.
. O Seminário, Livro 7 A Ética da Psicanálise. Rio de Janeiro: Jorge Zahar Ed., 1991.

. O Seminário, Livro 17 O Avesso da Psicanálise. Rio de Janeiro: Jorge Zahar Ed., 1992.

. Seminário 23. Le Sinthome. (1975-1976), (inédito).

LAPLANCHE, J. Problemáticas I: a Angústia. São Paulo: Martins Fontes, 1998.

Referências 